\title{
4
}

\section{Changing Spectrum of Chronic Immune Thrombocytopenic Purpura: New Face for an Old Disease}

\author{
Indu Sabnani and Patricia Tsang \\ Newark Beth Israel Medical Center New Jersey, \\ United States of America
}

\section{Introduction}

Characterized by low platelet counts, immune thrombocytopenic purpura (ITP) has been discovered to be an acquired autoimmune disorder since the mid-1900s (Evans et al., 1951). In the 21st century, the modern generation would shudder at Harrington and Hollingsworth's experiment they performed to search for the pathogenesis of ITP. By injecting themselves with $500 \mathrm{ml}$ of blood from a patient from low platelet counts, they developed the same bleeding disorder and were able to reproduce the disease in themselves (Harrington et al., 1951). Since that experiment, the pathogenesis and the therapeutic options of ITP have evolved by leaps and bounds. The traditional model of ITP is that of pathologic destruction of platelets by antiplatelet antibody. For many decades, this model of autoimmune thrombocytopenic purpura has shaped our understanding of the disorder and our therapeutic management of ITP (Buchanan et al, 1977, Hou et al. 1995, Fujisawa K et al. 1992). Recent studies have broadened our perspective beyond humoral dysregulation to include the cellular immune system and abnormalities of megakaryocytes as well (Olsson, et al., 2003, Ballem et al., 1987, McMillan et al., 2004). These recent findings have opened the door for new treatment possibilities for ITP.

In contrast to a more predictable clinical course of acute ITP, the pathogenesis, natural history and management of chronic ITP are significantly more diverse and rapidly evolving. The established treatment practices for chronic ITP have also undergone a major change. After a long period of standard treatment approach using steroids, splenectomy, and immunosuppressive therapy, a breakthrough came with the use of B-cell depletion therapy (Cines and McMillan, 2005). The availability of monoclonal antibody, rituximab, has led hematologists to reconsider the role of splenectomy in the frontline management of chronic ITP (Arnold et al., 2007). A new era has begun with the development of thrombopoietinmimetic agents that stimulate megakaryocytes to grow and produce platelets (Nurden et al., 2009).

Since chronic ITP remains a heterogeneous disorder; there is no consensus on the definite diagnostic criteria and management. In 1996, the American Society of Hematology published a landmark paper recommending guidelines to assist clinicians in the management of ITP (George et al., 1996). Since then, there have been tremendous advances in the management of both adult and pediatric ITP. These guidelines were updated by the 
American Society of Hematology in 2010 (Neunert et al., 2010). In addition, an International Working Group (IWG) of experts on ITP attempted to bring some uniformity to the diagnosis and management of ITP (Rodeghiero et al., 2009). Despite the serious efforts of scientists and specialty societies, the practicing hematologists are still left with many unanswered questions and dilemmas when it comes to treating this benign but challenging disease.

Until recently, adult ITP was considered a disease of young women. However, two recently published studies have shown otherwise (Schoonen et al. 2009, Abrahamson et al., 2009). In these series, the mean ages at presentation were over 50 years, with a slight female predominance (M:F ratio of 1.7:1). In contrary to acute ITP in children, adult ITP is usually insidious in onset, with platelet counts of $>20 \times 10^{9} / \mathrm{L}$. The incidence of chronic ITP is 5.8 to 6.6 per 100,000 in the adult population.

\section{Definition of chronic ITP}

While ITP in children usually pursues an acute and self-limited clinical course that responds well to treatment, ITP in adults tends to present as a chronic relapsing condition. Traditionally, the terms chronic ITP, refractory ITP, and chronic persistent ITP are used interchangeably and are used for chronic phase of the disease. Chronic or refractory ITP was previously defined as immune thrombocytopenia persisting for $>3$ months, failure to respond to splenectomy, and platelet count of less than $50 \times 10^{9} / \mathrm{L}$. The definition has become more confusing since the evolution of splenectomy sparing modalities of treatment.

The International Working Group (IWG) consensus panel of both adult and pediatric experts in ITP recently provided guidance on terminology, definitions and outcome criteria for this disorder (Proven et al., 2010). Primary ITP, as defined by the IWG, is platelet count less than $100 \times 10^{9} / \mathrm{L}$ in the absence of other causes or disorders that may be associated with thrombocytopenia. IWG used a higher platelet cutoff than the traditional criterion of $50 \mathrm{x}$ $10^{9} / \mathrm{L}$ based on the observation that there might be physiological variations among different racial groups and that the chances of developing persistent thrombocytopenia of less than $100 \times 10^{9} / \mathrm{L}$ over 10 years of follow-up seemed to be less in patients presenting with a platelet count between 100 and $150 \times 10^{9} / \mathrm{L}$.

The IWG also categorizes ITP as newly diagnosed (diagnosis to 3 months), persistent (3 to 12 months from diagnosis) or chronic (lasting for more than 12 months). However, these definitions may not apply to patients with secondary forms of ITP and have not been formally validated. Specifically, "persistent ITP" includes patients not achieving spontaneous remission or not maintaining therapeutic response after stopping treatment between 3 and 12 months from initial diagnosis. The category "chronic ITP" is reserved for patients with ITP lasting for more than 12 months.

The IWG standardization does not include the degree of thrombocytopenia in classifying the different phases of the disease. The severity of disease varies in patients. Mild, moderate, and severe thrombocytopenia is used commonly in clinical practice. There are no firm guidelines. However, mild thrombocytopenia typically ranges from 50 to $100 \times 109 / \mathrm{L}$, moderate thrombocytopenia from 20 to $50 \times 10^{9} / \mathrm{L}$, and severe thrombocytopenia under $20 \mathrm{x}$ $109 / \mathrm{L}$. The severity of thrombocytopenia may or may not correlate well with the risk of bleeding. It is well known that the severity and symptoms of ITP in the same patient can 
vary from time to time. Table 1 summarizes the different terminologies commonly used to define ITP.

\begin{tabular}{|c|c|}
\hline Category & Definition \\
\hline Primary ITP & $\begin{array}{c}\text { Platelet count less than } 100 \times 10^{9} / \mathrm{L} \text { in the absence } \\
\text { of other causes of thrombocytopenia }\end{array}$ \\
\hline Newly diagnosed ITP & From initial diagnosis to 3 months \\
\hline Persistent ITP & From 3-12 months of initial diagnosis \\
\hline Chronic ITP & ITP lasting for greater than 12 months \\
\hline Mild Thrombocytopenia & Platelet count between $50-100 \times 10^{9} / \mathrm{L}$ \\
\hline Moderate Thrombocytopenia & Platelet count between $20-50 \times 10^{9} / \mathrm{L}$ \\
\hline Severe thrombocytopenia & Platelet count below $20 \times 10^{9} / \mathrm{L}$ \\
\hline
\end{tabular}

Table 1. Commonly used definitions in ITP

\section{Diagnosis of chronic ITP}

Fifty years since the discovery of platelet autoantibodies, there is still no definitive laboratory diagnostic test for ITP. Despite the tremendous advances made in the understanding of the pathophysiology, the diagnosis of ITP remains one of exclusion. An initial complete history and physical examination is essential to identify evidence of bleeding and exclude other etiologies of thrombocytopenia or secondary ITP. Secondary causes of thrombocytopenia include autoimmune disorders as well as exposure to drugs (such as quinine), herbs, foods and other substances. A peripheral smear examination usually helps to exclude other hematological disorders, such as thrombotic thrombocytopenic purpura, leukemia, and pseudothrombocytopenia from platelet aggregation. Testing for hepatitis $\mathrm{C}$ and HIV infection is recommended for all patients presenting as ITP (Cines et al., 2005, 2009, 2010).

Glycoprotein-specific assays to detect platelet-associated IgG (PAIgG) autoantibodies lack sufficient sensitivity for them to be of use as a diagnostic tool. Therapeutic response to IVIG is considered by many as confirmatory of ITP, in the absence of identifiable causes of thrombocytopenia. As per American Society of Hematology guidelines, there is insufficient evidence for the utility of routine testing for anti-platelet antiphospholipid and antinuclear antibodies, and thrombopoietin levels. There have been recent reports achieving remission in chronic ITP patients with the eradication of Helicobacter pylori infection. Even though there is insufficient evidence to support routine testing for Helicobacter pylori organisms, patients with gastrointestinal symptoms should be investigated further.

Although 2010 ASH guidelines did not find evidence to support an age threshold for which bone marrow is recommended, most hematologists would favor performing bone marrow examination for patients over 60 years of age to rule out myelodysplasia. This practice is especially useful prior to splenectomy in these older patients who do not show good response to treatment. The diagnosis of ITP should always be reassessed during the course of treatment if any atypical clinical or laboratory abnormalities develop to suggest lupus and other autoimmune or hematological disorder. Table 2 outlines the utility of various diagnostic tests for diagnosing ITP according to current guidelines. 


\begin{tabular}{|c|c|c|}
\hline Diagnostic Evaluation & Recommended & Optional \\
\hline $\begin{array}{c}\text { Personal \& Family History of } \\
\text { Autoimmune Disorders }\end{array}$ & $\sqrt{ }$ & \\
\hline $\begin{array}{c}\text { Complete Blood Count and } \\
\text { Peripheral Smear Examination }\end{array}$ & $\sqrt{ }$ & \\
\hline $\begin{array}{c}\text { ESR ANA and Anticradiolipin } \\
\text { Antibodies }\end{array}$ & & $\sqrt{ }$ \\
\hline $\begin{array}{c}\text { Blood Group \& Direct } \\
\text { Antiglobulin Test }\end{array}$ & $\sqrt{ }$ & \\
\hline HCV \& HIV Serologies & $\mathrm{x}$ & $\begin{array}{c}\text { Prior to splenectomy in } \\
\text { patients over } 60 \text { years, with } \\
\text { poor response to medical } \\
\text { therapy }\end{array}$ \\
\hline $\begin{array}{c}\text { Antiplatelet Antibodies } \\
\text { Bone Marrow Aspiration and }\end{array}$ & $\mathrm{x}$ & \\
\hline Thrombopoietin Level & & \\
\hline
\end{tabular}

Table 2. Diagnostic tools for chronic ITP

\section{Pathogenesis}

Since the 1950s, ITP has been firmly established as an acquired autoimmune disorder characterized by low platelet count (Evans et al., 1951). In recent years, there have been significant new insights into the pathophysiologic mechanisms of ITP. Historically, the thrombocytopenia associated with ITP was attributed solely to autoantibodies causing platelet destruction. More recently, it has become evident that the pathophysiology in ITP is complex and multifaceted. In addition to a humoral-mediated mechanism, cytotoxic Tcells and impaired platelet production by abnormal megakaryocytes have recently been found to be important pathogenetic factors in subsets of patients. Our evolving knowledge of the pathogenesis of ITP has led to new therapeutic targets in the clinical management of ITP.

\subsection{Autoantibody-mediated platelet destruction}

In the mid-1900s, it was observed that when experimental subjects were infused with plasma from ITP patients, these subjects developed dose-dependent thrombocytopenia (Harrington et al., 1953). Subsequently, it was shown that the inciting plasma factor was an antiplatelet antibody and that ITP was autoimmune in nature (Schulman et al., 1965).

Platelet-associated autoantibodies are detectable in $50 \%$ to $70 \%$ of patients with ITP using currently available laboratory methods. Approximately $75 \%$ of the autoantibodies detected are directed against the platelet surface glycoprotein (GP) complexes GPIIb-IIIa and GPIb-IX (Hou, et al., 1995). Antibodies against other glycoproteins (GPIa-IIa, IV, and V) are less commonly found (Chang et al. 2003).

These autoantibodies are primarily of the IgG heavy chain type, but IgM and IgA may also be involved (Schulman, et al., 1965). The antibodies are secreted by autoreactive B-cells which are activated by autoreactive CD4+ helper T-cells. In fact, the pathway that leads to platelet destruction involves a complex interplay of the humoral and cellular immune systems. 
The initial trigger for the abnormal autoantibody response is unknown. The cause of this loss of self-tolerance probably varies among patients. However, the common pathway appears to involve CD4+ helper T-cells reacting with a specific platelet-associated antigen on the surface of an antigen-presenting cell (such as macrophage, dendritic cell or B-cell). These activated helper $\mathrm{T}$ cells produce cytokines that stimulate B-cells to produce specific antibodies. These cytokines can also lead to expansion of CD8+ cytotoxic T-cells.

The primary site of platelet destruction is the spleen, and to a lesser extent, the liver and bone marrow. In these organs, antibody-sensitized platelets are destroyed by phagocytic cells.

\subsection{Role of cytotoxic T-cells}

In $30 \%$ or more of the ITP patients with no detectable anti-platelet antibody (Harrington, et al., 1953), alternative mechanisms of platelet destruction are likely to play a role. Recent studies suggest that platelet lysis by CD8+ cytotoxic T-cells may be an important pathogenetic pathway in some ITP patients. These T-cells show increased expression of cytotoxic genes, including tumor necrosis factor a, perforin, granzyme A and granzyme B. In addition to causing lysis of platelets, cytotoxic T-cells may damage megakaryocytes in the bone marrow (Olsson et al, 2003). Therefore, downregulation of cytotoxic T-cell response serves as a potentially effective therapeutic target, especially in ITP patients who are refractory to conventional treatment regimens (Sabnani \& Tsang, 2007).

\subsection{Impaired platelet production}

Besides accelerated platelet destruction, abnormal megakaryocytic growth and development are involved in the pathogenesis of ITP. Bone marrow examination under the microscope characteristically reveals normal to increased numbers of megakaryocytes in ITP patients. There may also be a shift to younger forms of megakaryocytes. Despite an apparently adequate number of megakaryocytes, platelet production is impaired. Studies of platelet production have demonstrated decreased or normal turnover in greater than $70 \%$ of ITP patients, suggesting an impaired compensatory response of the megakaryocytes to ongoing platelet destruction (Chang et al., 2003; McMillan, et al., 2004). In fact, bone marrow ultrastructural studies have demonstrated abnormalities in $50 \%$ to $75 \%$ of megakaryocytes in ITP patients. These megakaryocytes show impaired maturation and platelet release, and are unable to adequately compensate for the peripheral platelet destruction (Houwerzijl, et al, 2004).

Produced primarily in the liver, thrombopoietin (TPO) is the hormone responsible for enhancing megakaryocytic maturation and platelet production (Kuter, 2007). When platelet levels are low, free TPO normally increases in the circulation, which then stimulates megakaryocyte proliferation. However, serum levels of TPO fail to increase appropriately in response to thrombocytopenia in ITP patients (Kogusi, et al., 1996). Since TPO binds to both megakaryocytes and platelets, free TPO becomes less available as TPO binds to an increased number of megakaryocytes in the marrow. Furthermore, as platelets to which TPO binds are cleared from the circulation at an increased rate, TPO in turn becomes limited and platelet production is reduced (Kogusi, et al., 1996). These observations involving impaired megakaryocytic growth and relative deficiency of TPO levels have opened new treatment possibilities that involve targeting TPO to stimulate megakaryocytic proliferation and platelet production in ITP. 


\section{Therapeutic challenges and options}

\subsection{Clinical course of ITP}

The clinical spectrum of ITP is as heterogeneous as its pathogenesis. Spontaneous remissions occur very rarely. Although the majority of patients with chronic ITP require some type of therapeutic intervention, most have favorable long-term outcomes. However, mortality and morbidity are substantial in patients with severe disease that is refractory to treatment. Despite undergoing splenectomy after initial steroid trial, approximately onethird of ITP patients fail to sustain platelets above $150 \times 109 / \mathrm{L}$, and $15 \%$ to $30 \%$ of these patients will require continuous therapy to sustain platelets above $30 \times 10^{9} / \mathrm{L}$. Patients with chronic ITP and persistent platelet counts below $30 \times 10^{9} / \mathrm{L}$ have a 4 -fold higher risk of mortality than that of the general population. Mortality attributable to thrombocytopenia is usually caused by severe bleeding and infection. Overall, approximately $10 \%$ of all patients with ITP are expected to develop refractory disease, posing significant challenge in clinical management. In general, the chances of remission lessen as the duration of chronic ITP increases.

\subsection{Decision to treat chronic ITP}

The decision to treat a patient is usually based upon the individual patient's risk of bleeding. Treatment of patients with ITP is influenced by multiple factors, such as the age of the patient, severity of the illness, and the anticipated natural history. At the present time, treatment for ITP is considered appropriate for symptomatic patients and for those at risk of bleeding. Other factors influencing the decision to treat include a previous history of bleeding episodes, active lifestyle (such as playing contact sports), as well as other risk factors for bleeding such as hypertension, cerebrovascular disease, antiplatelet therapy, and the need for surgery or other invasive procedures. In such situations, treatment can be intermittent for a limited duration unless symptomatic thrombocytopenia persists.

The main goal for treating chronic ITP should be to achieve hemostatic platelet count. Hemostatic platelet count can be defined as the platelet count safe enough in an individual patient to prevent bleeding. Except for patients with severe thrombocytopenia $(<20,000 \mathrm{x}$ $10^{9} / \mathrm{L}$ ), platelet count is not a reliable surrogate marker for the risk of serious bleeding. Hemostatic platelet count varies in different patients. Most of the studies have shown that the risk of bleeding increases with platelet counts of less than 20 to $30 \times 10^{9} / \mathrm{L}$. Generally, treatment for adults is recommended when platelets fall below 20 to $30 \times 10^{9} / \mathrm{L}$ to avoid lifethreatening bleeding episodes.

Management of patients with platelet counts between 30 to $50 \times 10^{9} / \mathrm{L}$ requires individualization and clinical judgment. Since the natural history of ITP varies in each individual patient, the most important factor in treating such ITP patient is to establish the individual record of symptomatology. While establishing the natural history of ITP, it is advisable to keep the platelet count above $30 \times 10^{9}$. Patients with platelet count greater than $50 \times 10^{9} / \mathrm{L}$ should be treated in the event of active bleeding or anticipated surgical procedures that carry a high risk of bleeding.

The management of chronic ITP varies from observation to aggressive treatment, including stem cell transplantation (Passabeg \& Rabusin, 2008). The most critical player in the management of ITP patient is an educated patient. It is strongly suggested that patients understand the full spectrum of options and uncertainties surrounding treatment of this disorder. The availability of technology and support groups has made patients education 
better. Therapeutic options for chronic ITP are reflective of our understanding of the various pathogenic mechanisms of ITP.

\subsection{Therapeutic challenges and dilemmas}

Despite recommendations from ASH and IWG, there is no single standard treatment of chronic ITP. Once again, treatment should be highly individualized based on the natural history of ITP in the particular individual. Selection of treatment modality is based on age, co-morbid conditions, anticipated efficacy and adverse effects, as well as physician and patient preferences. Overall, the outcome of ITP has improved significantly in the last two decades with the advent of better mapping of the pathophysiology and the availability of new therapeutic agents. Since no single agent is effective in all patients, selecting a treatment regimen that is effective with tolerable toxicity is a challenging task.

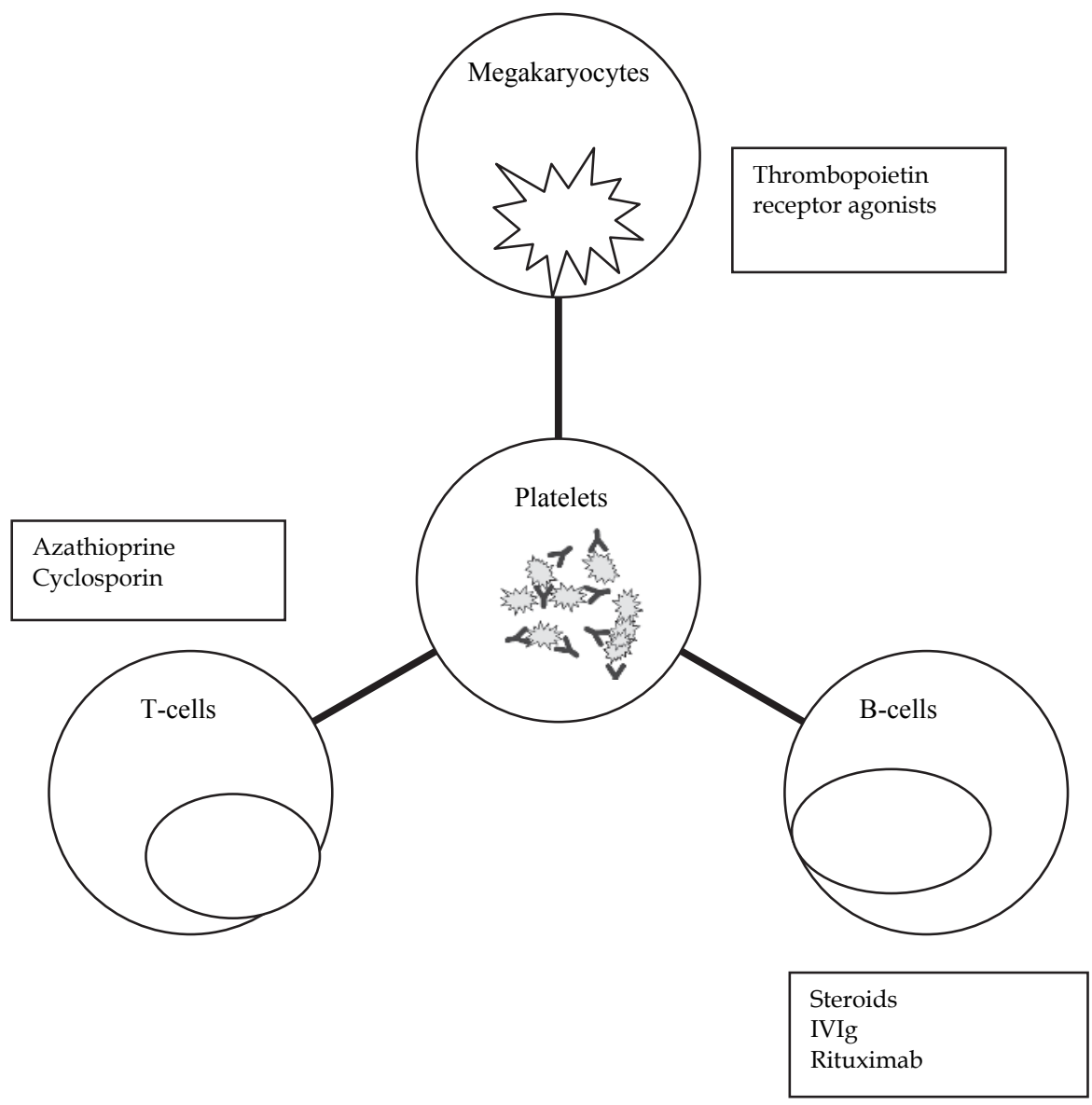

Fig. 1. Treatment modalities targeting various pathophysiologic mechanisms in chronic ITP 


\subsection{Initial treatment of chronic ITP:}

Once the diagnosis of persistent or chronic ITP is established and the need for the treatment is determined, underlying infection must be ruled out. Traditional modalities, such as steroids and immunosuppression, could be detrimental in the presence of infection. Intermittent courses of steroids and IVIG are used along with other immunosuppressive modalities. The most commonly used regimens are prednisone at a dose of $1 \mathrm{mg} / \mathrm{kg}$ per day orally. The popularity of pulse dosing of high-dose dexamethasone is rising ( $40 \mathrm{mg} / \mathrm{day}$ for 4 days) due to the convenience of short duration of treatment (Cheng et al., 2003). The reported success rate with pulse dexamethasone in chronic ITP is conflicting, and longlasting durable responses are generally not expected. Intravenous immunoglobulins (dose 1$2 \mathrm{gm} / \mathrm{kg}$ ) can also be used if there is a need to increase platelet count rapidly. Other alternative option is anti-D therapy. It is only recommended in Rh-positive and nonsplenectomized patients. Intermittent anti-D therapy can be used on a long-term basis but the potential risk of severe hemolysis should be taken into consideration.

\subsection{Second line treatment}

Until recently, splenectomy was the most common second line option for the treatment of refractory chronic ITP. The use of the anti-CD20 monoclonal antibody, rituximab, as a B-cell depletion therapy has gained tremendous popularity as a spleen saving treatment modality. Rituximab can be used alone or in combination with dexamethasone. However, the complete durable response rate is not as high as splenectomy( Schweizer et al. 2007). Relapsed patients can benefit from re-treatment with rituximab. Long-term immunosuppression and progressive multifocal encephalopathy remains potential serious complications with rituximab use.

\subsection{The role of splenectomy:}

Splenectomy still remains the most effective second line option and offers the highest rate of durable complete remissions. Splenectomy has been shown to lead to durable response in $60 \%$ to $70 \%$ of patients (Kumar et al. 2002). However, with the introduction of a number of novel treatments, some clinicians recommend delaying splenectomy until later in the course of the illness. Despite the reduced morbidity and mortality with laparoscopic splenectomy in the hands of experienced surgeons, prophylactic appropriate vaccination, and use of antibiotics promptly in the event of febrile illness in post-splenectomy patients; still fewer patients are opting for splenectomy.

\subsection{Therapeutic options after splenectomy failure}

Treatment of patients with refractory ITP following splenectomy is challenging. While many drugs are available, no one treatment is widely accepted (McMillan \& Durette, 2004). Intensive treatment should be reserved for patients with persistently low platelet counts in the presence of bleeding. Figure 2 shows an algorithm for managing ITP patients at different severities of disease. Other important considerations in the management of chronic ITP include the time to onset of efficacy, duration of benefit, and whether patients are able to maintain a response off therapy or if continued, the drug dosage necessary to maintain safe platelet counts.

Several immunosuppressive agents alone or in combination have shown some efficacy, including azathioprine (Quiquandon et al 1990), danazol, cyclophosphamide, 
mycophenylate mofetil (Hou et al. 2003), cyclosporine (Emilia et al. 2001), and vinca alkaloids. Another factor to consider when choosing an agent is patient preference for an oral agent administered daily, or an intravenous agent administered intermittently in an infusion clinic. Hematopoietic stem cell transplantation is used very rarely to treat ITP that has proven to be very refractory to treatment.
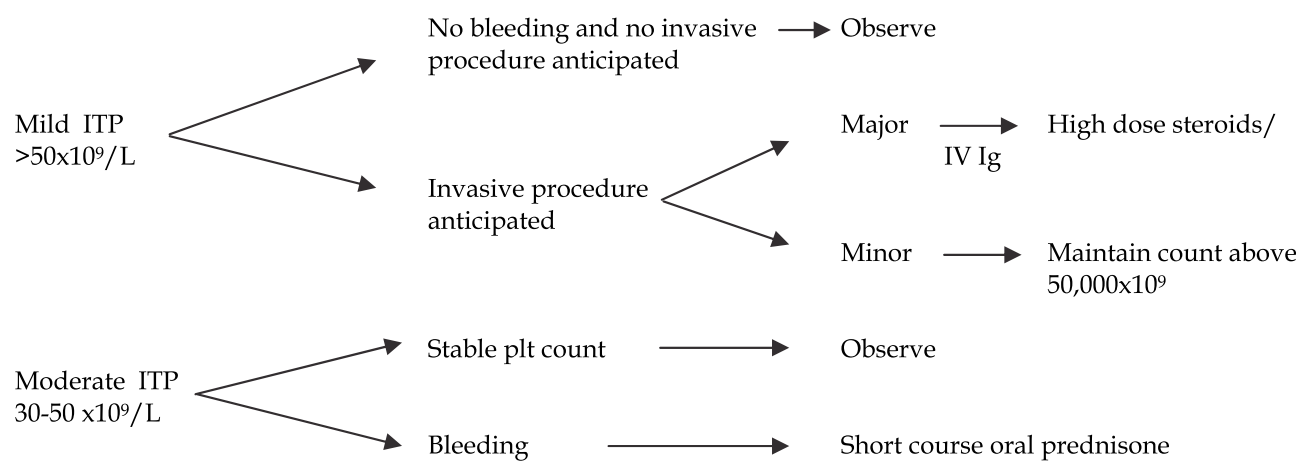

Anti-D therapy

Rituximab

High dose dexamethasone

Intermittent IV Ig

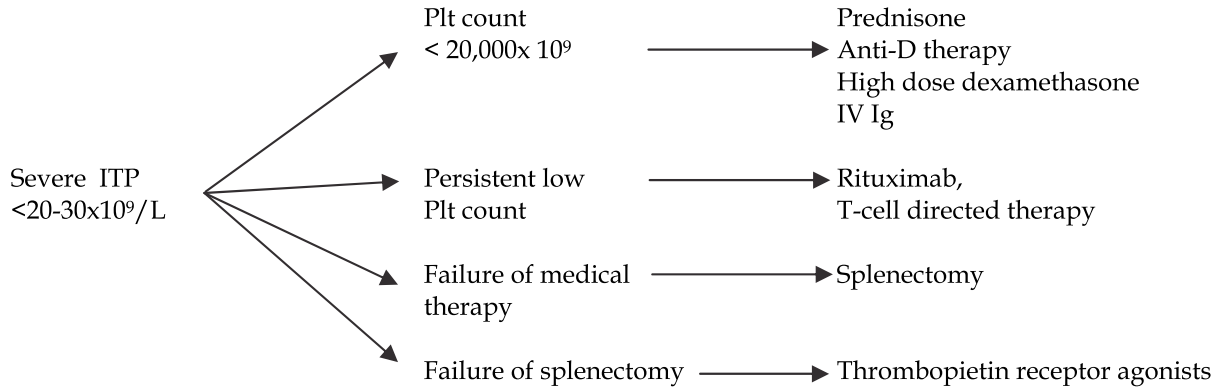

Fig. 2. Algorithm For the Management of Chronic ITP: “Individualize, individualize, and individualize"

Our better understanding of the immunopathogenesis has lead to the development of many novel therapies in the management of chronic ITP. Thrombopoietin receptor agonists (TRAs), which bind and activate the thrombopoietin (TPO) receptor to stimulate platelet production, have opened a new door in the management of chronic refractory ITP. Romiplastin (TPO peptide mimetic) and eltrombopag (nonpeptide TPO mimetic) are two recently approved agents for the treatment of refractory ITP (Burzynski, 2009). These agents have the advantage compared to recombinant TPO agonists of not causing the development of antibodies. The response rate of these agents ranges somewhere between $37 \%$ and $50 \%$. To date, the clinical experience with these novel agents for a relatively benign disease is limited. Despite showing a favorable safety profile to date, these agents may have potential long-term side effects, such as thrombosis and myelofibrosis. 


\section{Conclusion}

In summary, the diagnosis and management of chronic ITP require a highly individualized approach that is often based on the natural history of the disease in the particular patient as well as the experience of the physician. Published guidelines can certainly provide some guidance to the physicians but the decision of when and how to treat the thrombocytopenia will still depend upon the hematologists. Although ITP is an old disease, our recent understanding of the pathogenesis has caused a marked paradigm shift. For decades, steroids and IVIg have remained frontline treatment. Recently, the developments of newer therapies, such as rituximab and thrombopoietic agonists, have had a major impact on the management of ITP. A combination of different agents may be a useful approach in the future but a single uniform set of guidelines is difficult to establish. To date, optimizing the curative effects of the different therapies available remains a challenge.

\section{References}

Abrahamson, P., Hall, S., Feudjo-Tepie, M., Mitrani-Gold, F. \& Logie, J. (2009). The incidence of idiopathic thrombocytopenic purpura among adults: a population-based study and literature review. European Journal of Haematology, Vol.83, No.2, (August 2009), pp. 83-89, ISSN 0902-4441

Arnold, D., Dentali, F., Crowther, M., Meyer, R., Cook, R., Sigouin, C., Fraser, G., Lim, W. \& Kelton, J. (2007). Systematic review: efficacy and safety of rituximab for adults with idiopathic thrombocytopenic purpura. Annals of Internal Medicine, Vol.146, No.1, (January 2007), pp. 25-33, ISSN 0003-4819

Ballem, P., Segal, G., Stratton, J., Gernsheimer, T., Adamson, J. \& Slichter, S. (1987). Mechanisms of thrombocytopenia in chronic autoimmune thrombocytopenic purpura. Evidence of both impaired platelet production and increased platelet clearance. The Journal of Clinical Investigation, Vol.80, No.1, (July 1987), pp. 33-40, ISSN 0021-9738

Buchanan, G., Scher, C., Button, L. \& Nathan, D. (1977) Use of homologous platelet survival in differential diagnoses of chronic thrombocytopenia in childhood. Pediatrics, Vol.59, No.1, (January 1977), pp. 45-54, ISSN 0031-4005

Burzynski, J (2009) New options after first-line therapy for chronic immune thrombocytopenic purpura Am J Health Syst-Pharm - Vol 66 (Jan 15, 2009) suupl 2 pp. s11-s21

Chang, M., Nakagawa, P., Williams, S., Schwartz, M., Imfeld, K., Buzby, J. \& Nugent, D. (2003). Immune thrombocytopenic purpura (ITP) plasma and purified ITP monoclonal autoantibodies inhibit megakaryocytopoiesis in vitro. Blood, Vol.102, No.3, (August 2003), pp. 887-895, ISSN 0006-4971

Cheng, Y., Wong, R., Soo, Y., Chui, C., Lau, F., Chan, N., Wong, W. \& Cheng, G. (2003). Initial treatment of immune thrombocytopenic purpura with high-dose dexamethasone. New England Journal of Medicine, Vol.349, No.9, (August 2003), pp. 831-836, ISSN 0028-4793

Cines, D. \& Blanchette, V. (2002). Immune thrombocytopenic purpura. New England Journal of Medicine, Vol.346, No.13, (March 2002), pp. 995-1008, ISSN 0028-4793

Cines, D. \& Bussell, J. (2005). How I treat idiopathic thrombocytopenic purpura (ITP). Blood, Vol.106. No.7, (October 2005), pp. 2244-2251, ISSN 0006-4971 
Cines, D. \& McMillan, R. (2005). Management of adult idiopathic thrombocytopenic purpura. Annual Review of Medicine, Vol.56, (2005), pp. 425-442, ISSN 0066-4219

Evans, R., Takahashi, R., Duane, R., Payne, R. \& Liu, C. (1951). Primary thrombocytopenic purpura and acquired hemolytic anemia : evidence for a common etiology. Archives of Internal Medicine, Vol.87, No.1, (January 1951), pp. 48-65, ISSN 0003-9926

Emilia, G., Morselli, M., Luppi, M., Longo, G., Marasca, R., Gandini, G., Ferrara, L., D'Apollo, N., Potenza, L., Bertesi, M., \& Torelli, G. (2002). Long-term salvage therapy with cyclosporin A in refractory idiopathic thrombocytopenic purpura. Blood, Vol.99, No.4, (February 2001), pp. 1482-1485, ISSN 0006-4971

Fujisawa, K., Tani, P., O'Toole, T., Ginsberg, M. \& McMillan R. (1992). Different specificities of platelet-associated and plasma autoantibodies to platelet GPIIb-IIIa in patients with chronic immune thrombocytopenic purpura. Blood, Vol.79, No.6, (March 1992), pp. 1441-1446, ISSN 0006-4971

George, J., Woolf, S., Raskob, G., Wasser, J., Aledort, L., Ballem, P., Blanchette, V., Bussel, J., Cines, D., Kelton, J., Lichtin, A., McMillan, R., Okerbloom, J., Regan, D. \& Warrier, I. (1996). Idiopathic thrombocytopenic purpura: a practice guideline developed by explicit methods for the American Society of Hematology. Blood, Vol.88, No.1, (July 1996), pp. 3-40, ISSN 0006-4971

Harrington, W., Minnich, V., Hollingsworth, J., \& Moore, C. (1951). Demonstration of a thrombocytopenic factor in the blood of patients with thrombocytopenic purpura. Journal of Laboratory and Clinical Medicine, Vol.38, No.1, (July 1951), pp. 1-10, ISSN 0022-2143

Harrington, W., Sprague, C., Minnich, V., Moore, C., Aulvin, R. \& Dubach, R. (1953). Immunologic mechanisms in idiopathic and neonatal thrombocytopenic purpura. Annals of Internal Medicine, Vol. 38, No.3, (March 1953), pp. 433-469, ISSN 0003-4819

Hou, M., Peng, J., Shi, Y., Zhang, C., Qin, P., Zhao, C., Ji, X., Wang, X., \& Zhang, M. (2003). Mycophenolate mofetil (MMF) for the treatment of steroid resistant idiopathicthrombocytopenic purpura. European Journal of Haematology, Vol.70, No.6, (June 2003), pp. 353-357, ISSN 0902-4441

Hou, M., Stockelberg, D., Kutti, J. \& Wadenvik, H. (1995). Antibodies against GPIb/IX, GPIIb/IIIa, and other platelet antigens in chronic idiopathic thrombocytopenic purpura. European Journal of Haematology, Vol.55, No.5, (November 2005), pp. 307314, ISSN 0902-4441

Houwerzijl, EJ., Blom, NR., van der Want, JJ., Esselink, MT., Koornstra, JJ., Smit, JW., Louwes, H., Vellenga, E. \& Wolf, JT. (2004). Ultrastructural study shows morphologic features of apoptosis and para-apoptosis in megakaryocytes from patients with idiopathic thrombocytopenic purpura. Blood, Vol.103, (January 2004), pp. 500-506, ISSN 0006-4971

Kosugi, S., Kurata Y., Tomiyama, T., et al. (1996). Circulating thrombopoietin level in chronic immune thrombocytopenic purpura. British Journal of Hematology, Vol 93, No.3, (June 1996), pp. 704-706, ISSN 0007-1048

Kumar, S., Diehn, F., Gertz, M. \& Tefferi, A. (2002). Splenectomy for immune thrombocytopenic purpura: long-term results and treatment of postsplenectomy relapses. Annals of Hematology, Vol.81, No.6, (June 2002), pp. 312-319, ISSN 09395555 
Kuter, DJ. New thrombopoietic growth factors. (2007). Blood, Vol.109, No. 11, (June 2007), pp. 4607-4616, ISSN 1557-9190

McMillan, R. \& Durette, C. (2004). Long-term outcomes in adults with chronic ITP after splenectomy failure. Blood, Vol.104, No.4, (August 2004), pp. 956-960, ISSN 00064971

McMillan, R., Wang, L., Tomer, A., Nichol, J., \& Pistillo, J. (2004). Suppression of in vitro megakaryocyte production by antiplatelet autoantibodies from adult patients with chronic ITP. Blood, Vol.103, No.4, (February 2004), pp. 1364-1369, ISSN 0006-4971

Nurden, A., Villard, J. \& Nurden, P. (2009). New-generation drugs that stimulate platelet production in chronic immune thrombocytopenic purpura. Lancet, Vol.373, No.9674, (May 2009), pp. 1562-1569, ISSN 0140-6736

Nunert, C., Lim, W., Crowther, M., Cohen, A., Solberg, L. \& Crowther, MA ( 2011). The American Society of Hematology evidence-basedpractice guideline for immune thrombocytopenia. Blood, prepublished online, March 16, print ISSN 0006-4971, online ISSN 1528-0020),

Olsson, B., Andersson, P., Jernas, M., Jacobsson, S., Carlsson, B., Carlsson, L. \& Wadenvik, H. (2003). T-cell mediated cytotoxicity toward platelets in chronic idiopathic thrombocytopenic purpura. Nature Medicine, Vol.9, No.9, (September 2003), pp. 1123-1124, ISSN 1061-4036

Passweg, J. \& Rabusin, M. (2008). Hematopoietic stem cell transplantation for immune thrombocytopenia and other refractory autoimmune cytopenias. Autoimmunity, Vol.41, No.8, (December 2008), pp. 660-665, ISSN 0891-6934

Quiquandon, I., Fenaux, P., Caulier, M., Pagniez, D., Huart, J. \& Bauters, F. (1990). Reevaluation of the role of azathioprine in the treatment of adult chronic idiopathic thrombocytopenic purpura: a report on 53 cases. British Journal of Haematology, Vol.74, No.2, (February 1990), pp. 223-228, ISSN 0007-1048

Rodeghiero, F., Stasi, R., Gernsheimer, T., Michel, M., Provan, D., Arnold, D., Bussel, J., Cines, D., Chong, B., Cooper, N., Godeau, B., Lechner, K., Mazzucconi, M., McMillan, R. Sanz, M., Imbach, P., Blanchette, V., Kühne, T., Ruggeri, M. \& George, J. Standardization of terminology, definitions and outcome criteria in immune Thrombocytopenic purpura of adults and children: report from an international working group. Blood, Vol.113, No.11, (March 2009), pp. 2386-2393, ISSN 0006-4971

Sabnani, I. \& Tsang, P. (2006). Are clonal T-cell large granular lymphocytes to blame for unexplained haematological abnormalities? British Journal of Haematology, Vol.136, No.1, (January 2007), pp. 30-37, ISSN 0007-1048

Schoonen, W., Kucera, G., Coalson, J., Li, L., Rutstein, M., Mowat, F., Fryzek, J., \& Kaye, J. (2009). Epidemiology of immune thrombocytopenic purpura in the General Practice Research Database. British Journal of Haematology, Vol.145, No.2, (April 2009), pp. 235-244, ISSN 0007-1048

Schweizer, C., Reu, F., Ho, A. \& Hensel, M. (2007). Low rate of long-lasting remissions after successful treatment of immune thrombocytopenic purpura with rituximub. Annals of Hematology, Vol.86, No.10, (October 2007), pp. 711-717, ISSN 0939-5555

Shulman, N., Marder, V. \& Weinrach, R. (1965). Similarities between known antiplatelet antibodies and the factor responsible for thrombocytopenia in idiopathic purpura. Physiologic, serologic and isotopic studies. Annals of the New York Academy of Sciences, Vol.124, No.2, (June 1965), pp. 499-542, ISSN 0077-8923 


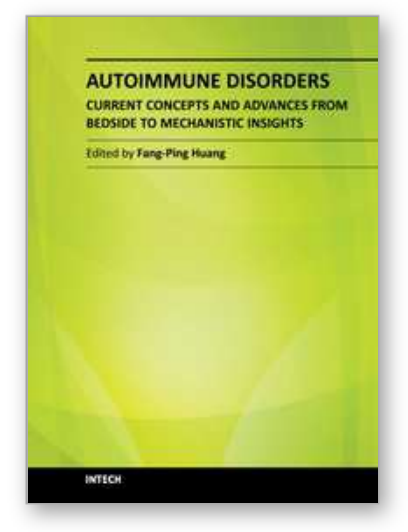

\author{
Autoimmune Disorders - Current Concepts and Advances from \\ Bedside to Mechanistic Insights \\ Edited by Dr. Fang-Ping Huang
}

ISBN 978-953-307-653-9

Hard cover, 614 pages

Publisher InTech

Published online 14, November, 2011

Published in print edition November, 2011

Autoimmune disorders are caused due to break down of the immune system, which consequently fails in its ability to differentiate "self" from "non-self" in the context of immunology. The diseases are intriguing, both clinically and immunologically, for their diversified clinical phenotypes and complex underlying immunological mechanisms. This book offers cutting-edge information on some of the specific autoimmune disease phenotypes, respective diagnostic and prognostic measures, classical and new therapeutic options currently available, pathogenesis and underlying mechanisms potentially involved, and beyond. In the form of Open Access, such information is made freely available to clinicians, basic scientists and many others who will be interested regarding current advances in the areas. Its potential readers will find many of the chapters containing in-depth analysis, interesting discussions and various thought-provoking novel ideas.

\title{
How to reference
}

In order to correctly reference this scholarly work, feel free to copy and paste the following:

Indu Sabnani and Patricia Tsang (2011). Changing Spectrum of Chronic Immune Thrombocytopenic Purpura: New Face for an Old Disease, Autoimmune Disorders - Current Concepts and Advances from Bedside to Mechanistic Insights, Dr. Fang-Ping Huang (Ed.), ISBN: 978-953-307-653-9, InTech, Available from: http://www.intechopen.com/books/autoimmune-disorders-current-concepts-and-advances-from-bedside-tomechanistic-insights/changing-spectrum-of-chronic-immune-thrombocytopenic-purpura-new-face-for-an-olddisease

\section{INTECH}

open science | open minds

\section{InTech Europe}

University Campus STeP Ri

Slavka Krautzeka 83/A

51000 Rijeka, Croatia

Phone: +385 (51) 770447

Fax: +385 (51) 686166

www.intechopen.com

\section{InTech China}

Unit 405, Office Block, Hotel Equatorial Shanghai

No.65, Yan An Road (West), Shanghai, 200040, China

中国上海市延安西路 65 号上海国际贵都大饭店办公楼 405 单元

Phone: +86-21-62489820

Fax: $+86-21-62489821$ 
(C) 2011 The Author(s). Licensee IntechOpen. This is an open access article distributed under the terms of the Creative Commons Attribution 3.0 License, which permits unrestricted use, distribution, and reproduction in any medium, provided the original work is properly cited. 